\title{
Solar Thermal Energy Storage with Phase Change Material - Heat Exchanger Design and Heat Transfer Analysis
}

\author{
Xi-li DUAN* \\ Faculty of Engineering and Applied Science, \\ Memorial University of Newfoundland \\ St. John's, NL, Canada, A1B 3X5 \\ e-mail: xduan@mun.ca, http://www.mun.ca \\ Stephan Ryan \\ Faculty of Engineering and Applied Science, \\ Memorial University of Newfoundland \\ St. John's, NL, Canada, A1B 3X5 \\ John Stamp \\ Faculty of Engineering and Applied Science, \\ Memorial University of Newfoundland \\ St. John's, NL, Canada, A1B 3X5
}

\author{
Josh Roul \\ Faculty of Engineering and Applied Science, \\ Memorial University of Newfoundland \\ St. John's, NL, Canada, A1B 3X5
}

\author{
Skylar Hodder \\ Faculty of Engineering and Applied Science, \\ Memorial University of Newfoundland \\ St. John's, NL, Canada, A1B 3X5
}

\begin{abstract}
Solar energy is clean and sustainable but intermittent in nature. Efficient storage of solar thermal energy is critical for its wider applications. This paper presents design and research on a thermal energy storage unit using phase change material (PCM). Aprototype of PCM heat exchanger with a helical coil tube was designed and fabricated for solar thermal energy storage, and was tested on a solar thermal experimental apparatus. This paper discusses the design concepts, selection of materials, as well as heat transfer analysis with the CFD tool Ansys Fluent.
\end{abstract}

Keywords-Thermal; Energy Storage; Heat Exchanger; Design; Phase Change Material; Heat Transfer; Simulation; Testing.

\section{INTRODUCTION}

Energy supply from many sustainable sources, such as solar thermal or wind, is intermittent in nature. Therefore efficient energy storage is critical for practical applications of these sustainable energies [1]. For residential solar thermal applications, conventional hot water systems have relatively low efficiency and limited capacity particularly at night and days without sunshine. To overcome these problems, phase change materials (PCMs) have been proposed to store thermal energy [2, 3]. PCMs have advantageous features such as nearly isothermal solid-liquid phase change and high energy storage capacity due to the latent heat of fusion.

Many types of phase change energy storage systems have been studied [4,5]. A tube and shell unit is one of the simplest designs and among the most commonly used. Materials used in a latent heat storage tank must be easy to find, inexpensive and environmentally friendly. The benefits of using an organic PCM is that they are generally abundantly available have a high latent heat of fusion, are chemically stable, and do not corrode other materials. The disadvantages include flammability and low thermal conductivities [6]. Inorganic PCMs are typically used in the high temperature range. The disadvantages of inorganic PCMs are the sub- cooling issue, as well as corrosion of the containment material [6,7].

This project aims to design, fabricate and analyze a solar thermal energy storage unit with phase change materials. A helical coil PCM heat exchanger prototype was fabricated and tested in a solar thermal apparatus at Memorial University. A computation fluid dynamics (CFD) tool was used to analyze thermal fluid characteristics of the PCM storage tank, with preliminary lab testing results presented.

\section{SYSTEM DESIGN}

Figure 1 shows Solid works models (a, b) and fabricated prototype (c, d) of a PCM heat exchanger (tank) for thermal energy storage. It consists of two end plates, a cylindrical shell, a spiral tube for heat transfer fluid (HTF), and 4 supporting struts.

Paraffin Wax was selected as the PCM, which fills the storage tank space between the HFT tube and the shell. Paraffin is typically in abundance and relatively inexpensive. It has an excellent latent heat of fusion, with a desirable operating temperature range $\left(\sim 50^{\circ} \mathrm{C}\right)$ for warm water applications. Single phase of water was selected as the heat transfer fluid. For the tank shell, polycarbonate was selected for this experimental porotype. Polycarbonate is durable, available, and easy to use with great heat/corrosion resistance. In addition, this material inherently acts as pseudo-insulator as it has a low thermal conductivity. With good transparency, this material also allows monitoring of 
the PCM melting and solidification process during lab testing.

A straight tube was analyzed in heat transfer simulation, but a spiral tube design, as shown in Fig. 1 (a) was selected for final fabrication. Both CFD simulation and lab testing proved that spiral tube has better heat transfer performance. Copper was chosen for the HTF tube for its exceptionally high thermal conductivity, low cost, and availability. Fig. 1 (d) shows the whole assembly with PCM in it, while Fig. 1 (c) shows the final unit with outer insulation for lab testing.

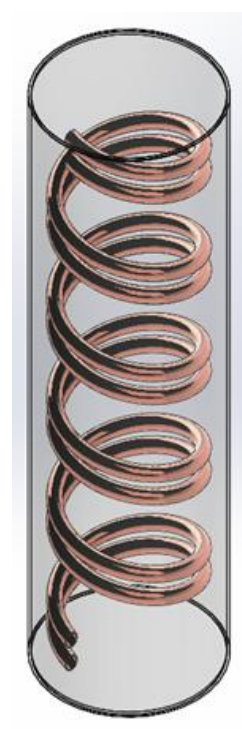

(a)

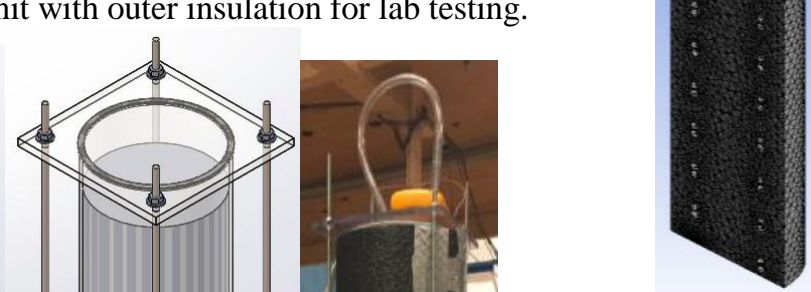

(a) approximately $321 \mathrm{~K}$, the melting point of the PCM. A very large portion of the volume is either fully liquid or undergoing phase change, but the PCM is still not fully melted yet.

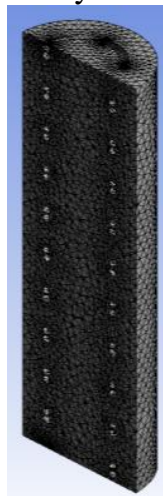

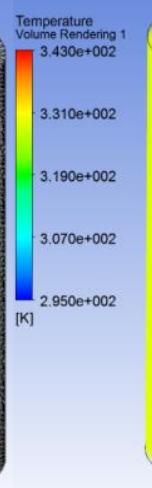

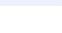

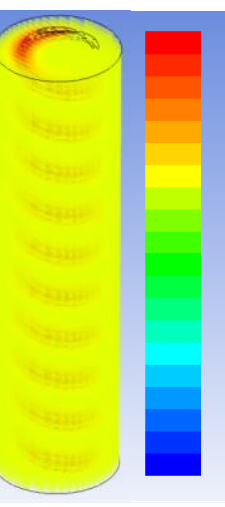

(b)

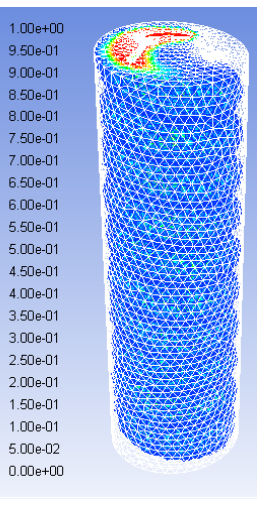

(c)
Figure 2. Melting of paraffin wax in a PCM heat exchanger with spiral tubes

\section{LAB TESTING}

The fully prepared PCM thermal energy storage unit, shown in Fig.1 (c), was tested on Memorial's solar thermal apparatus, shown in Fig.3, to verify the charging time and heat transfer process. The setup consists of a solar collector, a water tank, a pump for liquid flow, a compressor for air injection (when air-liquid two-phase flow is tested), flow meters, temperature and pressure sensors, and a data acquisition system. The working fluid is heated as it flows through the solar collector. Thenit is fed to the downstream water tank. The pump delivers the water back to the collector for reheating.

The PCM heat exchanger was connected to the system between the water outlet from the solar collector and the inlet to the water storage tank, to replace the water tank. The inlet water temperature for the PCM tank was measured at approximately 0.6 meters upstream, the outlet water temperature was measured at approximately 0.45 meters downstream, and a representative internal PCM temperature was measured near the inlet of the shell. The temperatures of these three points were measured every five minutes for approximately one hour.

Some preliminary testing results are shown in Fig. 4, including inlet and outlet water temperatures and the PCM internal temperatures during a 65 minutes of charging time.

It can be seen that the temperature differential is consistently less than one degree. This confirmed the assumption of a constant surface temperature in the copper tubing. Temperature of the paraffin wax is shown to steadily increase until approximately 51 degrees Celsius, at $~ 40$ minutes of charging. This information is critical as it demonstrates that there is indeed phase change occurring as the temperature stabilized. This value corresponds closely with the measured melting point of the wax. Due to temperature limitations of the tubing, this test only reached 
the melting point and early phase change period. A longer duration test will be conducted to test fully melted PCM.

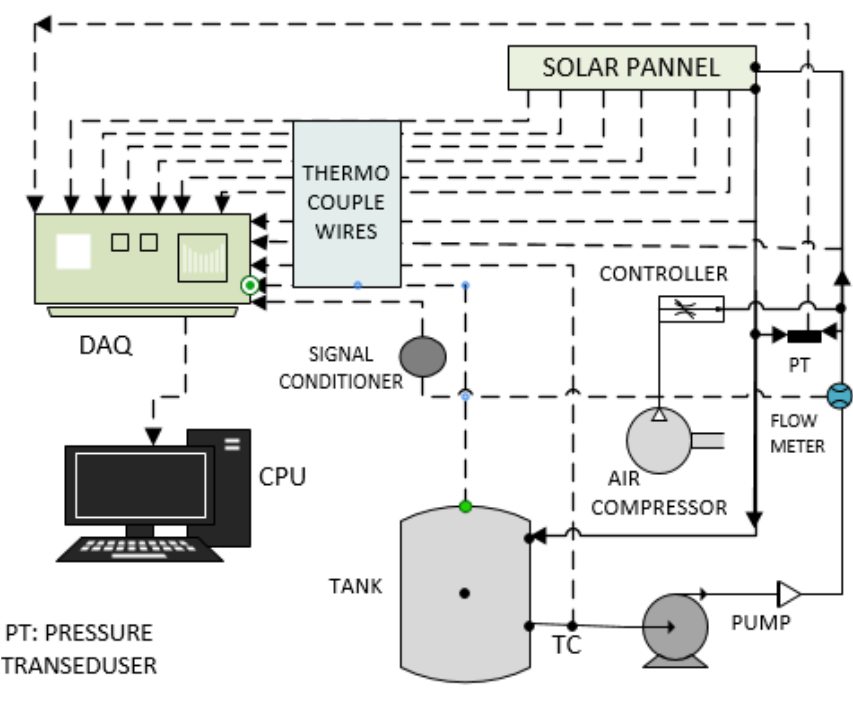

Figure 3. Solarthermal experimental apparatus and the tested PCM thermal storage unit

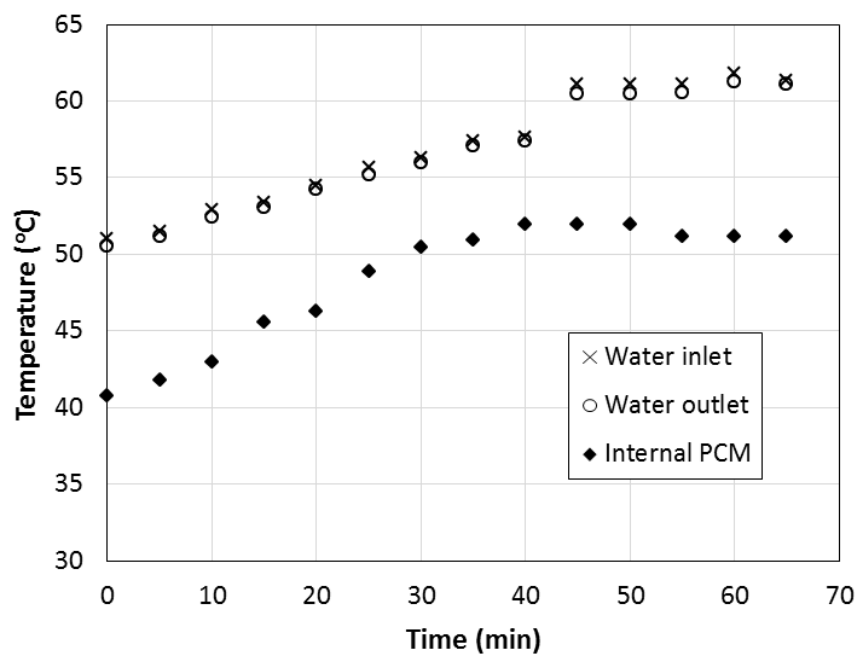

Figure 4. Lab testing results

\section{CONCLUSION}

APCM heat exchanger for latent storage of solar thermal energy was designed, fabricated, and analyzed numerically and experimentally. The unit contains paraffin wax, a cylindrical shell, and spiral tube for heat transfer fluid flow. CFD simulation of this design provided fundamental insight to the effects of design parameters. A prototype heat exchanger was successfully assembled for lab testing, which served as proof of concepts, confirmation of assumptions in the simulation, and provided useful preliminary data for future work to improve the design.

\section{REFERENCES}

[1] Chu, S., \&Majumdar, A. (2012). Opportunities and challenges for a sustainable energy future. Nature, 488(7411), 294-303.

[2] Akgün, M., Aydın, O., \&Kaygusuz, K. (2008). Thermal energy storage performance of paraffin in a novel tube-in-shell system. Applied Therm. Eng. 28(5), 405-413.

[3] Sarı, A.,Karaipekli, A. (2007). Thermal conductivity and latent heat thermal energy storage characteristics of paraffin/expanded graphite composite as phase change material. Applied Therm. Eng., 27(8), 1271-1277..

[4] Al-Abidi, A., Mat, S., Sopian, K., Sulaiman, Y., \& Mohammad, A. (2016). Heat Transfer Enhancement for PCM Thermal Energy Storage in Triplex Tube Heat Exchanger. Heat Transfer Eng., 37(7-8), 705-712.

[5] Nomura, T., Tsubota, M., Oya, T., Okinaka, N., \& Akiyama, T. (2013). Heat storage in direct-contact heat exchanger with phase change material. Applied Therm.Eng., 50(1), 26-34.

[6] Chiu, Justin Ning-Wei. Heat Transfer Aspects of Using Phase Change Material in Thermal Energy Storage Applications. (2011).

[7] Sharma, A., Tyagi, V. V., et al. (2009). Review on thermal energy storage with phase change materials and applications. Renew. Sust. Energ. Rev., 13(2): 318-345. 